\title{
Control gubernamental del gasto público en el Estado constitucional: reflexiones a propósito de la aprobación de las facultades sancionadoras de la Contraloría General en materia de responsabilidad administrativa funcional"
}

\author{
Governmental control of public expenditure in the \\ constitutional State: thoughts regarding General \\ Comptroller sanctioning powers approval on functional \\ administrative responsibility
}

\section{ERIKA GARCÍA COBIÁN CASTRO*}

Resumen: La doctrina constitucional se ha ocupado poco de la Contraloría General de la República y de su función de control sobre la ejecución y gestión de recursos públicos en el Estado. Esta situación se ha tratado de explicar en otras realidades en función del alto contenido presupuestario, contable y de auditoría de la actividad fiscalizadora atribuida constitucionalmente a esta clase de entidades ${ }^{1}$.

No obstante, la delimitación competencial de la Contraloría General de la República y su condición de organismo constitucional autónomo configuran una manifestación importante del Estado constitucional y su principio de división de poderes. Dicho organismo controla la ejecución del presupuesto público del Estado y contribuye a la protección de bienes constitucionales, como la legalidad de la ejecución presupuestal y la adecuada gestión de recursos públicos, la «eficiencia de las necesidades sociales», el buen funcionamiento de la administración estatal y la prevención de la corrupción, entre otros.

El presente artículo se propone analizar la misión constitucional de la Contraloría General de la República en el Estado constitucional, con el fin de contribuir a la promoción del proceso de «constitucionalización del ordenamiento jurídico» en el ámbito de la actuación e influencia de dicha entidad y la optimización de los bienes constitucionales que protege. Para tal efecto, se utilizará como objeto de análisis constitucional la reciente

El presente artículo se basa en el trabajo de investigación desarrollado por la autora para optar el grado de Magíster con mención en Derecho Constitucional, por la Pontificia Universidad Católica del Perú.

** Abogada por la Pontificia Universidad Católica del Perú. Máster en Derechos Fundamentales por la Universidad Carlos III de Madrid en España y máster en Estudios Latinoamericanos por la Universidad de Salamanca en España. Actualmente es asesora senior de la Cooperación Alemana en el Programa Buen Gobierno y Reforma del Estado, y dicta el curso de Derecho Constitucional en la Facultad de Derecho de la Pontificia Universidad Católica del Perú. Correo electrónico: egarciac@pucp.pe

1 Cf. De Vega BlázQuez, Pedro. «La configuración constitucional del Tribunal de Cuentas en España». Cuestiones Constitucionales, 1 (julio-diciembre 1999), p. 219 . Consulta: 13 de agosto 2013. En: <http://www.juridicas.unam.mx/publica/rev/cconst/cont/1/art/art8.htm> 
ley 29622, «Ley que modifica la ley 27785, Ley Orgánica del Sistema Nacional de Control y de la Contraloría General de la República, y amplía las facultades en el proceso para sancionar en materia de responsabilidad administrativa funcional».

Palabras clave: Estado constitucional - facultades sancionadoras - gasto público - Contraloría General - responsabilidad administrativa funcional

Summary: Constitutional doctrine has little addressed on the General Comptroller of the Republic and its controlling function of public resources execution and management. Efforts have been made to explain this situation in other realities, regarding high budgetary, accounting and auditing content needed to carry out auditing activities constitutionally assigned to this kind of entities.

Nevertheless, identifying competences of the General Comptroller of the Republic and its nature of autonomous constitutional body shapes an important expression of Constitutional State and the principle of powers division. This entity controls State's Public Budget execution contributing to constitutional property protection, legality of budget implementation and the appropriate management of public resources, also the «efficiency» of social needs, proper functioning of public administration and prevention of corruption, among others duties.

This article analyzes the constitutional mission of the General Comptroller in a Constitutional State promoting the process of given a constitutional status to the legal system in its area of influence, also optimizing constitutional properties protected. For such purpose, the 29622 recent law («Law that modifies the 27785 Organic Law of National Control System and the General Comptroller of the Republic extending powers in order to sanction in accordance of functional administrative responsibility») shall be used as object of constitutional analysis.

Key words: constitutional State - sanctioning powers - public expenditure General Comptroller - functional administrative responsibility

\footnotetext{
CONTENIDO: I.- ESTADO CONSTITUCIONAL, CONTROL EXTERNO DE LA EJECUCIÓN DEL PRESUPUESTO PÚBLICO Y ENTIDADES FISCALIZADORAS SUPERIORES.-II.LACONTRALORÍA GENERALDELAREPÚBLICAYELCONTROL GUBERNAMENTAL EN EL ORDENAMIENTO CONSTITUCIONAL PERUANO.III. REFLEXIONES SOBRE LA CONSTITUCIONALIDAD DE LAS FACULTADES DE LA CONTRALORÍA GENERAL PARA SANCIONAR EN MATERIA DE RESPONSABILIDAD ADMINISTRATIVO FUNCIONAL.- IV. REFLEXIÓN FINAL.
} 


\section{ESTADO CONSTITUCIONAL, CONTROL EXTERNO DE LA EJECUCIÓN DEL PRESUPUESTO PÚBLICO Y ENTIDADES FISCALIZADORAS SUPERIORES}

\section{I.1. Estado constitucional y control externo de la ejecu- ción presupuestaria}

El Estado constitucional es un modelo de Estado sujeto al derecho que ha reinterpretado los principios originales del Estado de derecho decimonónico o del constitucionalismo liberal del siglo XIX ${ }^{2}$ y perfeccionado su configuración en orden a garantizar mejor la dignidad de las personas frente al ejercicio del poder proveniente de cualquier poder del Estado o de poderes fácticos no estatales.

Una nota sustancial del Estado constitucional es el reconocimiento de la fuerza normativa de la Constitución y la subordinación del principio de legalidad al de supremacía de la Constitución. La ley, considerada en el Estado de derecho como la norma jurídica con primacía en el ordenamiento, pasa a ser una norma sujeta a la supremacía de la Constitución ${ }^{3}$. En tal sentido, la exigencia de someter la actividad del Poder Ejecutivo y del Poder Judicial a las reglas producidas por el Poder Legislativo evoluciona hacia la determinación de que los poderes públicos, entre ellos el Poder Legislativo, deben sujetarse al derecho, a un derecho más alto, dotado de fuerza normativa ${ }^{4}$, conformado por un conjunto de principios constitucionales superiores, sobre los que existe un consenso social suficientemente amplio ${ }^{5}$ y que reconoce un catálogo de derechos fundamentales, así como garantías para su protección.

Estos derechos, fundamentales en el Estado constitucional, comprenden la libertad del Estado de derecho y los derechos sociales y protegen contra la amenaza o violación proveniente de los poderes públicos, así como frente a los particulares y el poder de los privados, que ya no solo contarán con garantías para su protección en el ámbito estatal sino también en el internacional'.

La eficacia del principio de supremacía constitucional conlleva un proceso de «constitucionalización del ordenamiento jurídico», es decir, la transformación progresiva de dicho ordenamiento hacia su total impregnación por las normas constitucionales. Guastini anota como manifestaciones de la «constitucionalización del sistema jurídico»: (i) una Constitución rígida; (ii) la garantía jurisdiccional

2 Cf. Pozzolo, Susana. Neoconstitucionalismo y positivismo jurídico. Lima: Palestra, 2011, p. 18.

3 Ídem.

4 Cf. Zagrebelsky, Gustavo. El derecho dúctil. Ley, derechos, justicia. Novena edición Madrid: Trotta, 2009, p. 39; Cf. FERRAJOLI, Luigi. «Juspositivismo crítico y democracia constitucional». Isonomía. Revista de Teoría y Filosofía del Derecho, 16 (abril 2002), p. 14. México D.F.: ITAM.

5 Cf. ZAGREBELSKY, Gustavo. Ob. cit., pp. 39-40.

6 Cf. Ferrajol, Luigi. Ob. cit., p. 17.

CONTROL GUBERNAMENTAL DEL GASTO PÚBLICO EN EL ESTADO CONSTITUCIONAL: REFLEXIONES A PROPÓSITO DE LA APROBACIÓN DE LAS FACULTADES SANCIONADORAS DE LA CONTRALORÍA GENERAL EN MATERIA DE RESPONSABILIDAD ADMINISTRATIVA FUNCIONAL

GOVERNMENTAL CONTROL OF PUBLIC EXPENDITURE IN THE CONSTITUTIONAL STATE: THOUGHTS REGARDING GENERAL COMPTROLLER SANCTIONING POWERS APPROVAL ON FUNCTIONAL ADMINISTRATIVE RESPONSIBILITY 
de la Constitución; (iii) la fuerza vinculante de la Constitución; (iv) la sobreinterpretación de la Constitución; (v) la aplicación directa de las normas constitucionales; (vi) interpretación conforme de las leyes, y (vii) la influencia de las Constitución sobre las relaciones políticas?

Por su parte, también el principio de separación de poderes, en el esquema del Estado constitucional, adquiere un redimensionamiento de su contenido sin perder el fundamento de su origen, orientado al control del ejercicio del poder. Por tal razón se ha considerado que, más allá de una concepción rígida de división del poder sobre la base de tres organismos fundamentales: Legislativo, Ejecutivo y Judicial, la fidelidad al principio se expresa en la presencia de pesos y contrapesos en el Estado, compatible con la existencia de una multiplicidad de instituciones que asumen funciones especializadas en una relación de intervenciones de control y colaboración mutuas y recíprocas ${ }^{8}$.

Esta reconfiguración del principio de división de poderes tiene relación con la asunción de nuevas funciones por cada uno de los clásicos poderes estatales, con semejanzas a las que típica y exclusivamente realizaban algunos de sus pares, así como con la presencia de otros organismos constitucionales autónomos en la esfera estatal, que pueden considerarse en el mismo nivel de jerarquía o estatus que los poderes Ejecutivo, Legislativo y Judicial.

Para García Pelayo, el principio de división de poderes es mucho más complejo que el que formuló originalmente Montesquieu. Sin embargo, el propósito de impedir la concentración del poder como idea básica mantiene actualmente su vigencia y resulta coherente con la presencia de los organismos constitucionales autónomos en el escenario público. Para dicho autor, estos organismos son constitutivos o esenciales en la estructura del Estado. Reciben competencias y funciones especializadas, directamente de la Constitución, para cumplir determinadas finalidades fundamentales y garantizar el buen funcionamiento del modelo de Estado. Asimismo, tienen paridad de rango y relaciones de coordinación con los demás poderes y organismos constitucionales, todo lo cual implica que tengan autonomía y superioridad en el ámbito de su competencia?.

Una de las manifestaciones del principio de control, propio del Estado constitucional, es el control externo de la ejecución del presupuesto público y de la gestión económica y financiera del Estado, ejercido

7 Cf. GuAstinI, Riccardo. Estudios de teoría constitucional. México D.F.: Instituto de Investigaciones Jurídicas, 2001, pp. 153-183.

8 Cf. DiAz, Elías. Estado de derecho y sociedad democrática. Cuarta edición. Madrid: Cuadernos para el diálogo S.A., 1972, p. 32.

9 Cf. GarCIA Pelayo, Manuel. «El estatus del Tribunal Constitucional». Revista Española de Derecho Constitucional, I, I (1981), pp. 11-34. 
por un organismo constitucional autónomo o entidad de fiscalización superior a la que se asigna específicamente tal función estatal.

Entre la organización política y la hacienda pública existe una estrecha relación, dado que el control sobre la ejecución presupuestal procurará que el ejercicio económico y financiero de la administración pública se lleve a cabo respetando la voluntad de la representación nacional y en cumplimiento de los aspectos formales y jurídicos necesarios para alcanzar los objetivos previstos en la formulación presupuestal aprobada $^{10}$.

Dicho control es una de las más antiguas expresiones de la limitación del poder. La necesidad de ejercer el control externo sobre la función presupuestaria del gobernante o autoridad política se remonta al período de tránsito del Estado medieval al Estado moderno, cuando el Parlamento británico en formación del siglo XIII fue asumiendo como propia la facultad para consentir el presupuesto y aprobar los tributos ${ }^{11}$. Incluso las potestades legislativas del Parlamento se fueron ganando y arrancando del ámbito de poder del monarca, usando el arma financiera y la compulsión frente a las solicitudes del rey para conseguir fondos extraordinarios ${ }^{12}$.

Más nítidamente, en el siglo XVII el Parlamento se impone frente al rey como corolario de un período largo de tensiones entre ambas instituciones, generadas por el desconocimiento del monarca de sus obligaciones frente al Parlamento, entre las que se encontraba la aprobación de impuestos con el consentimiento de esta institución ${ }^{13}$. Es interesante anotar que el control parlamentario del presupuesto no se limitaba a la autorización de los tributos. La Cámara de los Comunes complementó el control supremo que tenía sobre la capacidad impositiva, con su facultad de determinar o prescribir los objetivos para los cuales se debería gastar el dinero público ${ }^{14}$.

Por otra parte, si bien en la historia francesa el consentimiento de los impuestos no fue una práctica regular, el control presupuestario se manifestó a través de los jueces de cuentas y la constitución de una Corte de Cuentas, cuya aparición se registra en la Edad Media. Esta institución se caracterizó por la especialización en asuntos financieros

10 Cf. Valles Vives, Francesc. El control externo del gasto público. Configuración y garantía constitucional. Madrid: Centro de Estudios Constitucionales, 2003, pp. 29-30. Cf. PALAO TABOADA, Carlos. "El control de la actividad financiera en un Estado democrático". En AAVV. La función de los Tribunales de Cuentas en la sociedad democrática. Encuentro Internacional 1984. Madrid: Tribunal de Cuentas, 1985. Consulta: 9 de setiembre de 2012. <http://www.bduimp.es/archivo/conferencias/ pdf/11-08_84_10079_07_Palao_Control_idc13525.pdf>

11 Cf. PlanAS, Pedro. Derecho parlamentario. Lima: Ediciones Forenses, 1997, p. 16.

12 Cf. Planas, Pedro. Regímenes políticos contemporáneos. Lima: Fundación Friedrich Ebert, 1997, p. 65.

13 Cf. PlanAS, Pedro. Regímenes políticos contemporáneos. Ob. cit., pp. 65-70.

14 Cf. VAlles VIVES, Francesc. Ob. cit., p. 33.

CONTROL GUBERNAMENTAL DEL GASTO PÚBLICO EN EL ESTADO CONSTITUCIONAL: REFLEXIONES A PROPÓSITO DE LA APROBACIÓN DE LAS FACULTADES SANCIONADORAS DE LA CONTRALORÍA GENERAL EN MATERIA DE RESPONSABILIDAD ADMINISTRATIVA FUNCIONAL

GOVERNMENTAL CONTROL OF PUBLIC EXPENDITURE IN THE CONSTITUTIONAL STATE: THOUGHTS REGARDING GENERAL COMPTROLLER SANCTIONING POWERS APPROVAL ON FUNCTIONAL ADMINISTRATIVE RESPONSIBILITY 
del Estado, entre los que se encontraba la prevención contra la diversidad monetaria y la imposición de la rendición de cuentas periódica para los gestores locales. La supresión de la Corte de Cuentas durante el período revolucionario se explica por la desconfianza que generaron los jueces del Antiguo Régimen dada su sujeción a la Monarquía y su relación con prácticas de corrupción. No obstante, los revolucionarios franceses del siglo XVIII no desconocieron el concepto del control de la gestión del presupuesto público, lo que se demuestra con la Declaración de los Derechos del Hombre y del Ciudadano, cuando reconoce el derecho de los ciudadanos a «comprobar, por sí mismos o por sus representantes, la necesidad de la contribución pública, de consentirla libremente, de vigilar su empleo y de determinar su cuota, la base la recaudación y la duración».

La experiencia de un control jurisdiccional sobre las cuentas del Estado se replica en España por influencia francesa, cuyos precedentes preconstitucionales más remotos pueden distinguirse en la Edad Media y en el Antiguo Régimen. La denominación de Contador Mayor de Cuentas se utilizaba desde mediados del siglo XIV, y el de Tribunal de la Contaduría Mayor de Cuentas desde mediados del siglo XVI ${ }^{15}$. Esta institución se mantuvo durante la modernidad con la finalidad atender las dificultades en la recaudación de tributos y en la ordenación de las cuentas, así como para fortalecer el poder y dominio del rey en un proceso de consolidación de las monarquías frente a los señores feudales.

Los antecedentes de la implantación de una entidad fiscalizadora superior en el Perú y del control sobre la actividad presupuestaria pueden encontrarse en la Colonia, específicamente en las acciones adoptadas por la Corona con la finalidad de establecer un sistema de garantías y control sobre los dineros del rey, especialmente, determinadas por las amenazas de una corrupción generalizada entre los funcionarios españoles ubicados en tierras americanas. La ineficiencia del sistema de control sobre la gestión y uso de las riquezas obtenidas en las colonias para el rey contribuía a producir filtraciones en el proceso de remisión de los tesoros a España. Se ha registrado que los oficiales reales disponían de los ingresos generados por la empresa colonial como si fueran propios, para fines estrictamente privados. La verificación de este problema dio lugar a que se propusiera al rey la creación de Tribunales de Cuentas en las Indias, lo que finalmente tuvo lugar el 24 de agosto de 1605, durante el reinado de Felipe III de Austria, cuando se dispuso que los Tribunales de Cuentas fueran tres: el de Lima, México y Santa Fe de Bogotá ${ }^{16}$.

15 Tribunal de Cuentas. Consulta: 9 de setiembre de 2012. En: <www.tcu.es> 
Contemporáneamente, y en el contexto del Estado constitucional, el ciclo presupuestario solo tiene sentido si se le observa en el marco del principio de separación de poderes y atendiendo a los conceptos de controles, frenos y contrapesos. En efecto, el Poder Ejecutivo elabora el proyecto de ley de presupuesto público, proponiendo una priorización de partidas presupuestarias y gasto público. Por su parte, el Parlamento, organismo que encarna la representación nacional, tiene el poder de aprobar el proyecto de presupuesto formulado por el gobierno y de habilitarlo para que lo ejecute de conformidad con la ley aprobada. Finalmente, el Parlamento u otro un organismo constitucional autónomo y especializado ejercerán el control de la ejecución de aquel presupuesto según la Ley de Presupuesto y otras normas presupuestarias. En este ciclo, como ocurre en otros ámbitos del Estado, ningún poder actúa, al menos teóricamente, sin que exista la facultad de ser controlado por el otro ${ }^{17}$.

Al respecto, Dromi afirma que: «el presupuesto es una manifestación más del control jurídico-político del Poder Legislativo sobre el Ejecutivo, como corolario del sometimiento de la actividad financiera del Estado al imperio de la ley, propio de todo Estado de derecho, y como expresión de la teoría de la separación de poderes» ${ }^{18}$.

Los alcances de la función de control sobre la actividad presupuestaria tienen relación directa con la efectividad de los derechos fundamentales. Así, tal como lo sostiene Torres Boursault, no puede hablarse de democracia sin que la administración de los medios limitados y escasos de los que dispone el Estado para desarrollar su acción, esté sujeta a mecanismos efectivos de control. El control financiero da respuesta a las exigencias de transparencia en la utilización de los recursos públicos y garantiza el cumplimiento de los derechos de la ciudadanía ${ }^{19}$. En tal sentido, el control de la gestión y ejecución presupuestal del Estado lleva aparejada la idea de que los recursos públicos deben cumplir con la finalidad de sostener servicios públicos eficientes y eficaces en la satisfacción de necesidades de las personas, con impacto directo sobre su calidad de vida y vigencia de derechos fundamentales.

17 Cf. VALLeS Vives, Francesc. Ob. cit., pp. 33-34.

18 Cf. Droml, José Roberto. «Constitución, gobierno y control». En Presupuesto y cuenta de inversión, instrumentos de gobierno y control. Buenos Aires: Ciudad Argentina, 1997, p. 200, citado por la Sentencia del Tribunal Constitucional expedida en el proceso competencial signado con expediente 004-2004-CC/TC, Fundamento Jurídico 6.

19 Cf. TORRES BOURSAULT, Leopoldo. «Democracia y control financiero». En La función de los Tribunales de Cuentas en la sociedad democrática. Encuentro Internacional 1984. Madrid: Tribunal de Cuentas, 1985, Consulta: 9 de setiembre de 2012. En: <http://www.bduimp.es/archivo/conferencias/pdf/1108_84_10079_02_Torres_Democracia_idc8700.pdf >

CONTROL GUBERNAMENTAL DEL GASTO PÚBLICO EN EL ESTADO CONSTITUCIONAL: REFLEXIONES A PROPÓSITO DE LA APROBACIÓN DE LAS FACULTADES SANCIONADORAS DE LA CONTRALORÍA GENERAL EN MATERIA DE RESPONSABILIDAD ADMINISTRATIVA FUNCIONAL

GOVERNMENTAL CONTROL OF PUBLIC EXPEN-

DITURE INTHE

CONSTITUTIONAL STATE: THOUGHTS REGARDING GENERAL COMPTROLLER SANCTIONING POWERS APPROVAL ON FUNCTIONAL ADMINISTRATIVE RESPONSIBILITY 


\section{II.2. Entidades de fiscalización superior: naturaleza jurídica y funciones}

Estas consideraciones ponen de relieve la relevancia del control presupuestario como función intrínseca al Estado constitucional, constituyendo una expresión del control político, en titularidad del Parlamento, y técnico, a cargo de las entidades fiscalizadoras superiores, sobre la organización, distribución y ejecución del presupuesto, formulado por iniciativa del Poder Ejecutivo y ejecutado por toda la administración pública.

Dada la alta especialización en la que derivaron las funciones del ejercicio presupuestario por los órganos de gobierno, los sistemas democráticos confirmaron la necesidad de consolidar y fortalecer a las entidades especializadas encargadas de auxiliar al Poder Legislativo en el ejercicio de su competencia de control de la gestión económicofinanciera de la administración, proporcionando información técnica y procesada sobre la ejecución presupuestaria. Estas entidades son los denominados órganos de control externo, entidades de fiscalización superior, tribunales de cuentas ${ }^{20}$ o contralorías generales.

Una entidad fiscalizadora superior puede definirse como el organismo público que, con independencia de su designación, constitución u organización, ejerce en virtud de su competencia jurídica la más importante función de auditoría pública en el Estado ${ }^{21}$. En tal sentido, tienen como función típica, la «verificación, censura de cuentas, revisión, fiscalización, control [o] inspección» ${ }^{22}$ del uso y gestión de los recursos públicos, como una manifestación del necesario control del gasto público de la administración en un Estado constitucional.

De la justificación de su existencia en el Estado constitucional y de la definición señalada, se deduce que resulta esencial a la naturaleza de una entidad fiscalizadora superior su condición de autonomía o independencia.

Sobre el particular, una idea central será que el control externo en materia de gestión presupuestaria debe ser realizado por un organismo que ofrezca garantías de imparcialidad y objetividad en el ejercicio de sus funciones y que asegure los instrumentos para detectar - y, de ser el caso, depurar - la responsabilidad en la que hayan podido incurrir los funcionarios a cargo del manejo de fondos públicos ${ }^{23}$.

20 Cf. VAlLES Vives, Francesc. Ob. cit., pp. 37-38.

21 Cf. INTOSAI. Organización Internacional de las Entidades Fiscalizadoras Superiores. Glosario en línea de terminología de fiscalización de la INTOSAI. Consulta: 19 de marzo de 2012. En: <http:// www.intosaiglossary.org/Main.aspx>

22 Definición de auditoría, Cf. INTOSAI. Organización Internacional de las Entidades Fiscalizadoras Superiores. Glosario en línea de terminología de fiscalización de la INTOSAI. Consulta: 28 de mayo de 2012. En: <http://www.intosaiglossary.org/Main.aspx>

23 Cf. Valles Vives, Francesc. Ob. cit., p. 42. 
Esta consideración sobre la autonomía se explica especialmente si se tiene en cuenta que una entidad fiscalizadora superior tiene un papel fundamental y, a su vez, particularmente complejo en el ámbito de la lucha contra la corrupción. Este emprendimiento requiere una plataforma jurídica de control que tenga sus cimientos en la imparcialidad, el apoliticismo, y principalmente, en la autonomía o independencia de los órganos de control ${ }^{24}$.

La Declaración de Lima sobre las Líneas Básicas de la Fiscalización ${ }^{25}$ establece que «las entidades fiscalizadoras superiores solo pueden cumplir eficazmente sus funciones si son independientes de la institución controlada y se hallan protegidas contra influencias exteriores».

Por tal razón, es preferible que una entidad fiscalizadora y su competencia sean previstas directamente por las constituciones, configurándolas como organismos constitucionales autónomos ${ }^{26}$ que ejercen el control externo técnico-jurídico de la actividad económica y ejecución del presupuesto en el Estado para la cautela de los recursos públicos ${ }^{27}$. En el mismo sentido,, la referida Declaración de Lima ha expresado que «las entidades fiscalizadoras superiores y el grado de su independencia deben regularse en la Constitución; los aspectos concretos podrán ser regulados por medio de leyes».

La misión principal y formulada de modo general que se asigna a las entidades fiscalizadoras superiores en un Estado democrático es la fiscalización de la actividad económico-financiera del Estado, priorizando la comprobación de la legalidad y la gestión eficiente de los recursos públicos ${ }^{28}$.

Una de las funciones específicas que identifica a estas entidades es su papel de asesoría y apoyo especializado a los Congresos o Parlamentos en materia presupuestal, procurando fortalecer el control político del órgano de representación nacional sobre el Poder Ejecutivo y la administración pública. En el marco de esta función se ubican los informes que la entidad fiscalizadora superior alcanza al Parlamento, los que pueden estar referidos a los resultados anuales de su actividad o a

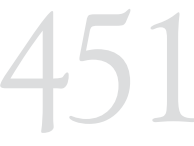

CONTROL GUBERNAMENTAL DEL GASTO PÚBLICO EN EL ESTADO

CONSTITUCIONAL: REFLEXIONES A

PROPÓSITO DE LA APROBACIÓN DE LAS FACULTADES SANCIONADORAS DE LA CONTRALORÍA GENERAL EN MATERIA DE RESPONSABILIDAD ADMINISTRATIVA FUNCIONAL

GOVERNMENTAL CONTROL OF PUBLIC EXPENDITURE IN THE CONSTITUTIONAL STATE: THOUGHTS REGARDING GENERAL COMPTROLLER SANCTIONING POWERS APPROVAL ON FUNCTIONAL ADMINISTRATIVE RESPONSIBILITY

24 Cf. Contraloría General de la República de Venezuela. “La corrupción y sus adversarios». Revista de Control Fiscal, 159 (setiembre-diciembre 2005), pp. 17-18.

25 Declaración de Lima sobre las Líneas Básicas de la Fiscalización firmada en el IX Congreso de la Organización Internacional de Entidades Fiscalizadoras Superiores, realizada en octubre de 1977.

26 Los organismos constitucionales autónomos son aquellos que instituciones que reciben su definición, posición, competencias esenciales y sus atributos esenciales directamente de la Constitución, y cuyo ejercicio actualiza el orden jurídico político fundamental. Cf. GARCíA PELAYO, Manuel. «El "status" del Tribunal Constitucional». Revista Española de Derecho Constitucional, 1. Madrid: Centro de Estudios Constitucionales, 1981, pp. 13 y ss.

27 Definición basada en la que se realiza sobre la configuración constitucional del Tribunal de Cuentas español Cf. De VeGa BLÁZqueZ, Pedro. Ob. cit. Consulta: 16 de mayo de 2012. En: <http://www. juridicas.unam.mx/publica/rev/cconst/cont/1/art/art8.htm>

28 Cf. VAlles Vives, Francesc. Ob. cit., p. 43. 
hechos de especial importancia y transcendencia que el Congreso de la República debe conocer para favorecer su función de investigación ${ }^{29}$.

Otra función claramente diferenciada de estas entidades en relación con el Parlamento es la auditoría que realiza sobre la Cuenta General del Estado, cuyos resultados debe poner en conocimiento de aquel con el fin de que tome una decisión sobre la aprobación de la Cuenta General elaborada por el Poder Ejecutivo.

La función de fiscalización o control que ejercen las entidades fiscalizadoras pueden asumir diversas modalidades, dependiendo de distintos criterios de clasificación.

a) Según el momento en que se realiza el control, este puede ser previo o posterior. Cuando se realiza antes de las operaciones financieras o administrativas, se trata de un control previo. $\mathrm{Si}$, por el contrario, se implementa una vez que las acciones objeto de control se han realizado, entonces se denomina control posterior ${ }^{30}$.

b) Con relación a su ubicación, el control gubernamental, ejercido por las entidades fiscalizadoras superiores, es externo. Este tipo de control se contrapone al control interno que realiza un órgano especializado que forma parte de la misma entidad pública, sobre otras dependencias de su organización. No obstante su ubicación, este órgano debe estar premunido de garantías de independencia necesarias para ejercer los controles dentro de su organización.

c) Si tomamos en cuenta como criterio el parámetro de fiscalización, podemos distinguir otras tres modalidades de control que asumen las entidades fiscalizadoras superiores. En tal sentido, puede identificarse el control de legalidad de la gestión financiera y presupuestal del Estado, que se entiende como la supervisión de la sujeción de las acciones y decisiones en materia de ejecución presupuestaria a la Ley de Presupuesto y otras normas que rigen el funcionamiento de la administración pública y la utilización de recursos estatales. A dicho control se encuentra asociada la función de identificación de responsabilidades, administrativas, civiles $o$ penales que pudieran constituir infracciones al ordenamiento jurídico y que deben ser investigadas para determinar la existencia de tales responsabilidades. Esta función contribuye a prevenir los actos irregulares y reducir los riesgos de corrupción, así como a fortalecer la cadena de valor anticorrupción, y en ella participan otras instituciones públicas, tales como el Ministerio Público y el Poder Judicial. 
Si el criterio de control es la racionalidad de las operaciones, entonces nos encontramos frente al tipo de control denominado control financiero.

Si se consideran como parámetros de control la economía, eficiencia, eficacia, rentabilidad, utilidad o resultados de la gestión financiera y presupuestal, entonces la entidad de fiscalización superior estará ejerciendo el control de gestión o desempeño. Los órganos y sistemas de control han modernizado su enfoque y métodos de intervención, que surgen de la idea de que la administración pública tiene la obligación de orientarse hacia resultados en la vida y derechos de las personas. Los métodos tradicionales de control de legalidad, documentario y examen de cuentas se ven complementados con un enfoque integral del control gubernamental que ha considerado métodos que apuntan fundamentalmente al análisis de gestión, a la determinación de los resultados y, en definitiva, a la precisión de la eficacia con que se han manejado las instituciones y caudales públicos, patrimonio de la colectividad. En tal sentido, actualmente las entidades fiscalizadoras superiores han asumido que es de interés público determinar no solamente si una administración ha manejado e invertido sus recursos respetando las normas y disposiciones legales aplicables, sino también, y de manera determinante, si ha alcanzado los objetivos planificados, y en tal caso, si lo ha hecho con eficiencia ${ }^{31}$.

\section{LA CONTRALORÍA GENERAL DE LA REPÚBLICA Y EL CONTROL GUBERNAMENTAL EN EL ORDENAMIENTO CONSTITUCIONAL PERUANO} En el ordenamiento constitucional peruano, la Contraloría General de la República es un organismo constitucional autónomo y órgano superior del Sistema Nacional de Control, encargado de la supervisión de la legalidad de la ejecución del presupuesto del Estado, de las operaciones de la deuda pública y de los actos de las instituciones sujetas a control (artículo 82 de la Constitución Política del Perú).

Sin embargo, dicho precepto no resulta suficiente para definir la misión constitucional de dicha institución. Es necesario analizar el bloque de constitucionalidad que corresponde a la delimitación de funciones y competencias de la Contraloría en el Estado peruano, revisando necesariamente la ley 27785, Ley Orgánica del Sistema Nacional de Control y de la Contraloría General de la República.

En tal sentido, debe considerarse que la Contraloría General, siendo el órgano rector del Sistema Nacional de Control, tiene la dirección o conducción del conjunto de órganos de control, normas, métodos

CONTROL GUBERNAMENTAL DEL GASTO PÚBLICO EN EL ESTADO CONSTITUCIONAL: REFLEXIONES A PROPÓSITO DE LA APROBACIÓN DE LAS FACULTADES SANCIONADORAS DE LA CONTRALORÍA GENERAL EN MATERIA DE RESPONSABILIDAD ADMINISTRATIVA FUNCIONAL

GOVERNMENTAL CONTROL OF PUBLIC EXPENDITURE IN THE CONSTITUTIONAL STATE: THOUGHTS REGARDING GENERAL COMPTROLLER SANCTIONING POWERS APPROVAL ON FUNCTIONAL ADMINISTRATIVE RESPONSIBILITY 
y procedimientos, estructurados e integrados funcionalmente, destinados a ejercer el control gubernamental. Esta modalidad de control en el Estado es aquella supervisión, preventiva o correctiva, que se realiza sobre los actos y resultados de la gestión pública, evaluando los sistemas de administración, gerencia y control, en atención a criterios de eficiencia, eficacia, economía, transparencia, legalidad y fidelidad a los lineamientos de política y planes de acción, en forma descentralizada (artículos 6 y 12 de la ley 27785).

De forma expresa, la Ley Orgánica de la Contraloría General establece que el control gubernamental externo que realizan los componentes de dicho sistema puede ser de legalidad, de gestión, financiero, de resultados, de evaluación del control interno u otros que sean útiles en función de la entidad y la materia de control (artículo 8). De este modo, la Contraloría General de la República tiene expresas atribuciones para implementar una importante gama de modalidades de control, considerando las características especiales del objeto y materia de la supervisión.

Resulta especialmente relevante que la misma Ley orgánica de la Contraloría General obligue a la institución a «orienta[r] su accionar al fortalecimiento y transparencia de la gestión de las entidades, la promoción de valores y la responsabilidad de los funcionarios y servidores públicos» (artículo 16). Ello se encuentra en directa relación con la obligación de contribuir y promover la transparencia, ética pública y lucha contra la corrupción en el Estado, sus dependencias y funcionarios.

Para el cumplimiento efectivo de sus funciones, la Ley Orgánica de la Contraloría General le reconoce a esta institución un conjunto de atribuciones, entre las cuales se encuentran: (i) acceso a los registros, documentos e información de las entidades, aun cuando sean secretos o pertenezcan a particulares que hayan tenido relación con las entidades públicas; (ii) ordenar a los órganos del sistema que realicen las acciones de control que evalúe necesarias; (iii) supervisar y garantizar el cumplimiento de las recomendaciones que se deriven de los informes de control; (iii) en los casos en los que de la ejecución de una acción de control se deriven indicios de comisión de delito o daño económico contra el Estado, dispondrá el inicio de acciones legales pertinentes por el procurador público de la Contraloría General o del sector o el representante de la entidad bajo control; (v) presentar anualmente al Congreso de la República el informe de evaluación de la Cuenta General de la República; (vi) interpretar la normativa de control gubernamental con carácter vinculante; (vii) emitir opinión previa sobre la adquisiciones y contrataciones que tengan carácter de secreto militar u orden interno exonerados de licitación, concurso público o adjudicación directa; 
asimismo sobre la ejecución y pago de presupuestos adicionales de obra pública, así como de endeudamiento; (viii) recibir y tramitar denuncias ciudadanas; (ix) fiscalizar las declaraciones juradas de los funcionarios públicos, y (x) sancionar a los funcionarios o servidores públicos que cometan infracciones contra la administración pública y en las que se derive responsabilidad administrativa funcional, entre otras.

Esta última atribución se incorporó a través de la ley 29622, del 6 de diciembre de 2010, que modificó la ley 27785, Ley Orgánica de la Contraloría General de la República, ampliando la potestad sancionadora de este organismo en materia de responsabilidad administrativa funcional, desarrollada posteriormente por el decreto supremo 023-2011-PCM, que aprueba el reglamento de infracciones y sanciones para la responsabilidad administrativa funcional derivada de los informes emitidos por los órganos del Sistema Nacional de Control.

Efectivamente, la Contraloría General, a partir de la vigencia de la ley 29622, se encuentra habilitada para identificar, investigar, determinar responsabilidad administrativa y sancionar, de ser el caso, a funcionarios y servidores públicos en el ámbito de su control, respecto de los actos que conlleven el incumplimiento de deberes legales y que generen perjuicio económico o grave afectación al servicio público, debidamente tipificados en la Ley Orgánica del Sistema Nacional de Control y Contraloría General, y especificados en el reglamento de infracciones y sanciones para la responsabilidad administrativa funcional derivada de los informes de control.

Esta atribución corresponde a la modalidad de control gubernamental de legalidad directamente vinculada con la función de la Contraloría General de cautelar los recursos del Estado, promover valores y la responsabilidad de los funcionarios y servidores públicos y la prevención de la corrupción.

La legitimidad del control de legalidad y las facultades para sancionar las infracciones identificadas se evidencia mejor si tenemos en cuenta que la administración pública es una organización instrumental al cumplimiento de las finalidades del Estado, que administra y gestiona recursos públicos para la entrega de bienes y servicios sociales a los ciudadanos y ciudadanas, en el marco de un Estado constitucional ${ }^{32}$. La desviación de los recursos, bienes y servicios estatales, infringiendo previsiones legales, impacta gravemente en la calidad de vida y derechos de las personas, así como en el funcionamiento de un Estado al servicio de la ciudadanía. De allí la importancia de que el control 
sobre la ejecución del presupuesto se valga de mecanismos que aseguren su eficacia frente a irregularidades e incumplimiento de deberes de los funcionarios públicos, que, en el ámbito de la administración pública y la gestión de recursos estatales, generen perjuicio al Estado y, por ende, a la ciudadanía que recibe sus servicios y prestaciones.

No obstante, tanto el control de legalidad como las específicas facultades sancionadoras en materia de responsabilidad administrativa funcional deberán implementarse sin que constituyan un factor de parálisis en la gestión pública y en armonía con los principios de legalidad, debido proceso y ne bis in idem. Al respecto, se ha señalado sobre el control de legalidad que:

La norma debe servir de instrumento indispensable de gobierno, a través del cual sus programas políticos y aspiraciones de voluntad cobran vigencia general, impersonal e imperativa para toda la colectividad [...]. Resulta importante que el auditor reconozca permanentemente este doble rol, para que su actitud evaluativa no solo se ciña al primer aspecto (control de apego del administrador a la ley) sino que contemple que el mismo ordenamiento debe funcionar como elemento conductista (no entrampador) de las sanas, correctas y transparentes decisiones gerenciales ${ }^{33}$.

En definitiva, la Contraloría General de la República en el Perú corresponde a la figura de una entidad fiscalizadora superior, directamente prevista en la Constitución como un organismo autónomo, cuya misión es la cautela de los fondos y presupuestos públicos a través del control de la ejecución y gestión presupuestal. Para tal efecto, supervisa el correcto funcionamiento de la administración estatal, la transparencia y la probidad en el ejercicio de la función pública. Sin embargo, el ejercicio del control gubernamental, y particularmente el control de legalidad sobre funcionarios y servidores públicos para la determinación de responsabilidad administrativa funcional, debe realizarse en armonía con la Constitución, y, particularmente, con respeto a los principios de legalidad, debido proceso, ne bis in idem, entre otros.

Por ello, la reflexión constitucional que se desarrolla a continuación, alrededor de la potestad sancionadora de la Contraloría General, busca esbozar algunos criterios que contribuyan a encauzar la aplicación del procedimiento administrativo sancionador e interpretar las disposiciones que lo regulan con arreglo a la Constitución, y específicamente, con respeto al principio ne bis in idem, para que las finalidades constitucionales que subyacen al reconocimiento de la potestad sancionadora se concreten con la legitimidad que

33 MORÓN URBINA, Juan Carlos. «Auditoría a situaciones jurídicas o auditoría a procedimientos». Boletín de Control, 3 (setiembre 1996), p. 4. Contraloría General de la República del Perú. 
corresponde al Estado constitucional, y en la dirección del proceso de constitucionalización del Derecho en este ámbito.

\section{REFLEXIONES SOBRE LA CONSTITUCIONALIDAD DE LAS FACULTADES DE LA CONTRALORÍA GENERAL PARA SANCIONAR EN MATERIA DE RESPONSABILIDAD ADMINISTRATIVA FUNCIONAL EN RELACION CON EL PRINCIPIO $N E B I S$ IN IDEM}

\section{III.1. Aprobación de la ley 29622 y cuestionamientos a su constitucionalidad}

Noobstantela existencia de su marcoinstitucional, laContraloríaGeneral de la República consideró, en su oportunidad ${ }^{34}$, que las facultades con las que contaba para el cumplimiento de su misión constitucional resultaban insuficientes para asegurar la eficacia de la función y posición del control gubernamental en el Estado, especialmente frente a la identificación de responsabilidades y sanción de funcionarios públicos que, en el manejo de los recursos del Estado, incurriesen en responsabilidad administrativa funcional. Señaló que el hecho de que fuera la propia entidad a la que perteneciese un funcionario público la encargada de sancionar por los supuestos de responsabilidad administrativa funcional identificada en los informes de control contribuía a la prescripción, la disminución de sanción o la impunidad de los actos irregulares que afectaban el presupuesto público ${ }^{35}$.

En tal sentido, el 17 de agosto de 2010 la Contraloría General presentó el proyecto de ley 4210/2010-CGR, que proponía innovar el régimen de procesamiento y sanción de responsabilidad administrativa funcional identificada en los Informes de Control, con el fin de implementar un esquema uniforme y ordenado de infracciones graves y muy graves y de un procedimiento especial en la esfera competencial de la Contraloría General de la República ${ }^{36}$.

Finalmente, luego de su debate en la Comisión de Fiscalización y Contraloría, el proyecto de ley fue aprobado en el pleno del Congreso de la República, en primera votación, el 18 de noviembre de 2010. La autógrafa fue promulgada el 6 de diciembre del mismo año, convirtiéndose en la ley 29622, «Ley que modifica la ley № 27785, Ley Orgánica del Sistema Nacional de Control y de la Contraloría General de la República, y amplía las facultades en el proceso para sancionar

34 Nos referimos al período anterior a la entrada en vigencia de la ley 29622, en el que no contaba con la potestad sancionadora por responsabilidad administrativo-funcional.

35 Exposición de motivos del proyecto de ley 4210/2010-CGR.

36 lbíd.

CONTROL GUBERNAMENTAL DEL GASTO PÚBLICO EN EL ESTADO CONSTITUCIONAL: REFLEXIONES A PROPÓSITO DE LA APROBACIÓN DE LAS FACULTADES SANCIONADORAS DE LA CONTRALORÍA GENERAL EN MATERIA DE RESPONSABILIDAD ADMINISTRATIVA FUNCIONAL

GOVERNMENTAL CONTROL OF PUBLIC EXPENDITURE IN THE CONSTITUTIONAL STATE: THOUGHTS REGARDING GENERAL COMPTROLLER SANCTIONING POWERS APPROVAL ON FUNCTIONAL ADMINISTRATIVE RESPONSIBILITY 
en materia de responsabilidad administrativa funcional». La norma se publicó al día siguiente en el diario oficial El Peruano.

Aun cuando las facultades sancionadoras se promovieron para fortalecer la protección de los recursos públicos y la eficacia del control gubernamental, así como para contribuir a la probidad administrativa y la lucha contra la corrupción, el proyecto de ley para su aprobación recibió algunos cuestionamientos de naturaleza constitucional, tanto de determinadas instituciones públicas — v.g. Ministerio Públicoy Autoridad Nacional del Servicio Civil— como de opiniones especializadas en el ámbito constitucional y administrativo.

El Ministerio Público señaló que las facultades sancionadoras excedían el marco competencial de supervisión atribuido a la Contraloría General por la Constitución y su ley orgánica, y que las funciones de control interno e imposición de sanciones corresponderían a los titulares de cada entidad $^{37}$.

Algunos especialistas en derecho administrativo afirmaron que se configuraría un exceso en la atribución de poder a la Contraloría General que podría afectar el Estado de derecho y el estatuto de los funcionarios públicos, y expresaron cuestionamientos a la misma configuración de la potestad sancionadora contemplada en el proyecto de ley, relativos a una alegada vulneración de principios como los de legalidad, debido proceso y proporcionalidad, entre otros ${ }^{38}$.

Adicionalmente, conviene apuntar que uno de los principios que encontramos, especialmente involucrado en el análisis de esta situación es el principio del ne bis in idem, que si bien se deriva del principio del debido proceso, tiene entidad propia. Dicho principio puede definirse de modo general como la prohibición de procesar o sancionar a la misma persona dos veces por los mismos hechos y por idéntico fundamento, y en tal sentido, la proscripción del ejercicio arbitrario y desproporcionado del ius puniendi del Estado.

En relación con las facultades sancionadoras reconocidas a la Contraloría General por la ley 29622, dicho principio debería impedir que los funcionarios y servidores públicos sean procesados o sancionados más de una vez por los mismos hechos y bajo el mismo fundamento, especialmente en el contexto de la relación entre las infracciones administrativas contempladas en la citada ley y su reglamento, y los tipos penales correspondientes a los delitos contra la administración pública, contemplados en el Código Penal.

37 Oficio 730-2010-MP-FN del 6 de octubre de 2010, remitido al presidente del Congreso de la República, César Alejandro Zumaeta Flores, por el Ministerio Público.

Oficio 258-2010-SERVIR/GG-OAJ, del 31 de agosto de 2010.

38 Informe jurídico «Observaciones al proyecto de Ley № 4210/2010-CG» remitido al Congreso de la República con fecha 22 de setiembre de 2010. 


\section{III.2. Alcances sobre la constitucionalidad de la ley 29622}

\section{III.2.1. Compatibilidad de la potestad administrativo-disciplinaria con la naturaleza institucional de la Contraloría General y su configuración constitucional}

La caracterización y misión de la Contraloría General en un Estado constitucional, así como su particular configuración en la Constitución peruana de 1993, no resultan, en principio, incompatibles con el ejercicio de funciones de control y sanción de funcionarios y servidores públicos por actos de incumplimiento de deberes legales que generan responsabilidad administrativa funcional en el ámbito de la utilización de los recursos públicos. Tales funciones constituirían mecanismos directamente vinculados con la efectividad de la misión que se le ha atribuido constitucionalmente, es decir, la protección del presupuesto y recursos públicos.

Sibien estas competencias no se prevén expresamente en la Constitución, no resultan incompatibles con el ordenamiento constitucional si tenemos en cuenta que en el Estado constitucional se admite el reconocimiento de «poderes implícitos», definidos como aquellos que, sin estar expresamente contemplados en la Carta fundamental, resultan absolutamente necesarios para que los organismos constitucionales puedan desempeñar de la mejor forma las funciones que les son atribuidas por la Constitución ${ }^{39}$.

Sobre el particular, es interesante anotar que en América Latina podemos encontrar que las entidades de fiscalización superior que ejercen el control de legalidad, acompañadas de facultades sancionadoras por responsabilidad administrativo funcional, son Chile ${ }^{40}$, Costa Rica ${ }^{41}$, Ecuador $^{42}$ y Venezuela ${ }^{43}$.

III.2.2. Compatibilidad del reconocimiento a la Contraloría General de facultades sancionadoras en materia de responsabilidad administrativa funcional con la distribución y delimitación de competencias constitucionales en el Estado

Por otra parte, el reconocimiento de la potestad sancionadora a la Contraloría General de la República tampoco resulta incompatible con la distribución y delimitación de competencias propias de nuestro ordenamiento constitucional, atribuidas a distintos organismos y entidades, para controlar la actuación de funcionarios públicos,

39 Tribunal Constitucional. Sentencia recaída en el expediente 013-2002-Al/TC. Fundamentos Jurídicos 1 y 2.

40 Texto refundido, coordinado y sistematizado de la Ley de Organización y Atribuciones de la Contraloría General de la República, ley 10336; artículos 133, y siguientes.

41 Ley 7428, Ley Orgánica de la Contraloría General de la República, capítulo V.

42 Ley 2002-73, Ley Orgánica de la Contraloría General del Estado, artículo 39.

43 Constitución Bolivariana de Venezuela, artículo 289.

CONTROL GUBER-

NAMENTAL DEL

GASTO PÚBLICO

EN EL ESTADO

CONSTITUCIONAL:

REFLEXIONES A

PROPÓSITO DE LA

APROBACIÓN DE

LAS FACULTADES

SANCIONADORAS

DE LA CONTRALO-

RÍA GENERAL EN

MATERIA DE RES-

PONSABILIDAD

ADMINISTRATIVA

FUNCIONAL

GOVERNMENTAL

CONTROL OF

PUBLIC EXPEN-

DITURE IN THE

CONSTITUTIONAL

STATE: THOUGHTS

REGARDING

GENERAL COMP-

TROLLER SANC-

TIONING POWERS

APPROVAL ON

FUNCTIONAL

ADMINISTRATIVE

RESPONSIBILITY 
determinar la responsabilidad administrativa disciplinaria e imponer sanciones derivadas de aquella.

Es interesante anotar que el diseño jurídico nacional en materia de responsabilidad administrativa funcional o disciplinaria no reserva potestades sancionadoras exclusivamente para las entidades públicas respecto de los funcionarios y servidores que las integran. Se reconoce también legitimidad constitucional para ejercer el control externo disciplinario sobre los funcionarios y servidores públicos a entidades como el Consejo Nacional de la Magistratura respecto de jueces y fiscales en el ámbito de la administración de justicia, o a la Autoridad Nacional del Servicio Civil respecto del personal de la administración estatal, a través de la actuación del Tribunal del Servicio Civil.

Por otra parte, es preciso recordar que, según se ha señalado anteriormente, el principio de separación de poderes y su redimensionamiento en el Estado constitucional es compatible con la existencia de una multiplicidad de organismos que cumplen funciones especializadas en el Estado y que mantienen entre sí relaciones de control y colaboración. En tal sentido, las competencias asignadas a cada poder o institución del Estado pueden tener naturaleza semejante o similar a las que típicamente realizan otros poderes, sin embargo ellas tienen una expresión, limitada, relativa y restringida ${ }^{44}$, determinada por criterios como la especialización.

Así, la potestad reconocida a la Contraloría General en materia de responsabilidad administrativa funcional, aun cuando pudiera conllevar algunas semejanzas con la potestad disciplinaria de otras entidades públicas en el ámbito de la administración estatal o con la función jurisdiccional para determinar responsabilidades penales por conductas típicas que atenten con la administración pública, no será inconstitucional si su intervención se encuentra en relación directa y delimitada por el cumplimiento de su misión institucional de control de la ejecución presupuestaria, si respeta el principio de proporcionalidad y debido proceso en la persecución y sanción de las conductas infractoras, y si su actuación cumple con la finalidad de colaboración con otros poderes y organismos autónomos para la consecución de la cautela de los recursos públicos, la prevención de la corrupción y el correcto funcionamiento de la administración pública.

La ley 29622 delimita la potestad sancionadora de la Contraloría General a los hechos y responsabilidades identificadas en las acciones de control y contenidas en el respectivo informe de control. Por lo tanto, la competencia no se aplicará al universo de las irregularidades

44 Entre otras, Tribunal Constitucional. Sentencia recaída en el expediente 004-2004-CC/TC, Fundamentos Jurídicos 23 y 24. 
verificadas en la administración pública, sino solo a aquellas que afecten o perjudiquen el uso de los recursos públicos de forma grave y muy grave, y que hayan sido objeto de una acción e informe de control. Las irregularidades leves o que no han sido identificadas en acciones e informes de control se mantienen en el ámbito administrativo disciplinario de las entidades públicas de las que forman parte los funcionarios y servidores públicos (artículos 45 y 46). Finalmente, las conductas más graves que se encuentren tipificadas en el Código Penal serán competencia del Ministerio Público y del Poder Judicial.

\section{III.2.3. Compatibilidad de las facultades sancionadoras de la Contraloría General de la República, contenidas en la ley 29622, con relación al principio ne bis in idem}

\section{III.2.3.1. Afectación del texto de la ley 29622 al principio ne bis in idem}

\section{a. Ámbito normativo y contenido del principio ne bis in idem}

El principio y derecho ne bis in idem proscribe la doble persecución o sanción a la misma persona por los mismos hechos y con idéntico fundamento, en línea con la interdicción de la arbitrariedad, así como con los principios de legalidad y proporcionalidad propios del Estado constitucional.

El ne bis idem ha sido definido por la jurisprudencia constitucional en el Perú como un «principio implícito en el derecho al debido proceso, reconocido por el artículo 139, inciso 3), de la Constitución», señalando que su vulneración exige constatar la conjunción de tres identidades distintas en la intervención persecutoria y punitiva del Estado: identidad de la persona perseguida (eadem persona), identidad del hecho u objeto de persecución (eadem res) e identidad de la causa de persecución o identidad de fundamento (eadem causa petendi) ${ }^{45}$.

Uno de los aspectos más complejos en la aplicación del mencionado principio es la determinación de la identidad de fundamento o causa de persecución y sanción, que impediría o justificaría, según sea el caso, la persecución y sanciones múltiples.

Lo que debe entenderse por la identidad de fundamento o identidad de la razón entre intervenciones sancionadoras respecto de una persona y de unos determinados hechos, no es un tema pacífico ni sencillo en el ámbito de la potestad punitiva del Estado. Este asunto se ha abordado en la doctrina jurisprudencial del Tribunal Constitucional peruano, sin que se haya generado un criterio uniforme, consistente ni consolidado

CONTROL GUBERNAMENTAL DEL GASTO PÚBLICO EN EL ESTADO CONSTITUCIONAL: REFLEXIONES A PROPÓSITO DE LA APROBACIÓN DE LAS FACULTADES SANCIONADORAS DE LA CONTRALORÍA GENERAL EN MATERIA DE RESPONSABILIDAD ADMINISTRATIVA FUNCIONAL

GOVERNMENTAL CONTROL OF PUBLIC EXPENDITURE IN THE CONSTITUTIONAL STATE: THOUGHTS REGARDING GENERAL COMPTROLLER SANCTIONING POWERS APPROVAL ON FUNCTIONAL ADMINISTRATIVE RESPONSIBILITY 
para verificar dicha identidad frente a la posibilidad de que se active más de una intervención estatal sancionadora ${ }^{46}$.

Uno de los criterios tradicionales que se ha postulado en el derecho para determinar la existencia o no de identidad de fundamento es el que corresponde a la tesis de la autonomía de responsabilidades, tesis que no compartimos, como se expondrá más adelante. Esta teoría asume que no existe identidad de fundamento cuando las intervenciones estatales punitivas provienen de dos órdenes jurídicos distintos, como en el caso de la intervención administrativa sancionadora (disciplinaria en el caso de funcionarios y servidores públicos) y la intervención jurisdiccional penal. Se sostiene que en este supuesto las pretensiones sancionadoras del Estado pueden activarse simultánea y independientemente por corresponder a dos razones o fundamentos diferentes, basados en la diferencia entre la naturaleza de los bienes jurídicos que son protegidos por cada uno de los órdenes jurídicos en cuestión (administrativo disciplinario y jurisdiccional penal).

Sostiene que la potestad administrativa disciplinaria es la que la administración ejerce sobre los funcionarios y agentes que forman parte de su organización, con la finalidad de proteger, por un lado, la organización y funcionamiento del ámbito interno de la administración, y por el otro, para garantizar bienes o valores propios de la administración, como la probidad de los funcionarios, la dignidad profesional de la administración o la ética pública» ${ }^{47}$.

Asimismo, se ha afirmado que «la sanción administrativa asegura expectativas referidas al funcionamiento global de un sector del tráfico social, y tiene como finalidad únicamente que los sectores no colapsen $»^{48}$. Así, no exigiría el cumplimiento del principio de lesividad de bienes jurídicos, funcionando como una respuesta ante conductas formales de simple desobediencia a reglas de ordenación. Esta razón para justificar la intervención administrativa diferiría de aquella que justifica la intervención penal, pues esta última sí exigiría la puesta en peligro o lesión de bienes jurídicos valorados socialmente y que trascienden el ámbito interno de la administración ${ }^{49}$.

46 Puede consultarse la revisión de jurisprudencia sobre el tema en GARCIA COBIÁN, Erika. «Reflexiones sobre la identidad de fundamento en la aplicación del principio ne bis in idem a partir de la jurisprudencia del Tribunal Constitucional en el Perú». En INSTITUTO IBEROAMERICANO DE DERECHO CONSTITUCIONAL y otros. Memoria del X Congreso Iberoamericano de Derecho Constitucional. Lima, 2009, pp. 283-301.

47 Cf. García de Enterría, Eduardo y Tomás Ramón Fernández. Curso de Derecho Administrativo. Tomo II. Primera edición peruana. Lima: Palestra, 2011, pp. 1070-1071.

48 Cf. García Cavero, Percy. Derecho penal económico. Parte general. Lima: ARA 2003, p. 72. Citado por CARO CORIA, Carlos. «El principio de ne bis in idem en la jurisprudencia del Tribunal Constitucional». En Jurisprudencia y doctrina penal constitucional. Segundo Seminario. Lima: Tribunal Constitucional - Palestra Editores S.A.C., 2006, pp. 305-306.

49 Cf. CARO Coria, refiriendo la posición de García Cavero. En CARO CoriA, Carlos. Ibíd. 
Por lo tanto, cuando los procesos y sanciones pertenecieran de forma diferenciada a cada uno de estos ámbitos, nunca se verificaría la identidad de fundamento entre ambos órdenes de intervención, y así siempre se justificarían la persecución y aplicación simultánea de sanciones provenientes del derecho administrativo y del derecho penal.

La concepción de la autonomía de responsabilidades, se complementa además con la posición de que los funcionarios y servidores públicos mantienen unas relaciones especiales de sujeción con la administración para la conservación y protección de bienes institucionales internos o especiales, lo que legitimaría el establecimiento de un régimen disciplinario propio y autónomo en el ámbito administrativo, independientemente de la intervención del derecho penal y, muchas veces, exento de las garantías y derechos, tales como el debido proceso, ne bis in idem, legalidad y proporcionalidad ${ }^{50}$.

Con relación al caso materia de análisis, el criterio de la autonomía de responsabilidades llevaría a descartar, automática y apriorísticamente, la identidad de fundamento entre las intervenciones del derecho administrativo sancionador (disciplinario) y el derecho penal, concurrentes respecto de los hechos observados en el informe de control, vinculados con la actuación irregular de los funcionarios o servidores públicos investigados. Así, quedaría justificada la apertura del procedimiento administrativo sancionador y del proceso judicial penal por los mismos hechos, así como la aplicación de diversas sanciones, aun cuando, desde un enfoque basado en el Estado constitucional, podrían compartir el mismo fundamento de punición.

Las consecuencias arbitrarias y desproporcionadas de tales posturas sobre los derechos fundamentales han dado lugar a una corriente crítica que sostiene la unidad del ius puniendi del Estado, así como la vigencia de los derechos al debido proceso y ne bis in idem, entre otros, en la relación entre los funcionarios públicos y la administración. Los cuestionamientos a la tesis de las relaciones especiales de sujeción, han llegado a afirmar que esta proviene de un sólido conservadurismo, propio de concepciones absolutistas y contrario a los principios del Estado de derecho ${ }^{51}$.

50 Cf. García de EnterRía, Eduardo y Tomás Ramón Fernández. Ob. cit., pp. 1069-1072.

51 Cf. Rando Casermeiro, Pablo. La distinción entre el derecho penal y el derecho administrativo sancionador. Un análisis de política jurídica. Valencia: Tirant lo Blanch, 2010, p. 85. Rando Casermeiro recoge un conjunto de autores que se han manifestado críticamente frente a la tesis de las relaciones especiales de sujeción. Así, menciona, entre otros, a DíEZ RIPOLLÉs, José Luis. "La huelga de hambre en el ámbito penitenciario". Cuadernos de Política Criminal, 30 (1986), pp. 498-500; MAPELLI Caffarena, Borja. Las consecuencias jurídicas del delito. Cuarta edición. Thomson-Civitas, 2005, pp. 154-155; HUERTA TOCILDO, Susana. «llícito penal e ilícito de funcionarios». En DíEz RIPOLLÉs, José Luis, Carlos Ma. Romeo Casabona, Luis Gracia Martín, Juan Felipe Higuera Guimerá. La ciencia del derecho penal ante el nuevo siglo. Libro homenaje al profesor doctor Don José Cerezo Mir. Madrid: Tecnos, 2002, pp. 43 y ss; GÓMEZ TOMILLo, Manuel. Derecho administrativo sancionador. Parte general. Teoría general y práctica del derecho penal administrativo. Cizur Menor: ThompsonAranzadi, pp. 200-206; OCTAVIO DE TOLEDO Y UBIETO, Emilio. La prevaricación del funcionario público. Madrid: Civitas, 1980, p. 295. 
Por su parte, esta tesis alternativa que afirma la unidad del ius puniendi estatal se inscribe en el modelo de Estado constitucional, afirmando que la potestad sancionadora estatal, en general, tiene un carácter instrumental a la protección de bienes jurídicos valiosos socialmente. Así, tanto la previsión del ámbito administrativo sancionadordisciplinario como la del ámbito jurisdiccional penal tienen como raíz común el ius puniendi del Estado y comparten la finalidad de proteger bienes o intereses jurídicos valiosos, con un sustrato en los derechos y bienes constitucionalmente protegidos. Así, compartimos la idea de que el fenómeno sancionador del Estado es uno solo, homogéneo, y tiene identidad sustancial ${ }^{52}$.

Al respecto, Asúa Batarrita señala que también la administración pública tiene un cometido promocional derivado de la configuración del Estado social, que consiste en su carácter instrumental para la promoción y efectividad de derechos constitucionales de la persona. Sostiene que las instituciones públicas, a través de sus agentes y funcionarios y por medio de la prestación de los servicios de interés general, garantizan la viabilidad de los derechos fundamentales ${ }^{53}$.

Por lo tanto, en el ámbito administrativo sancionador-disciplinario, se comprende que la protección del adecuado ejercicio de las funciones públicas no se ejerce en beneficio del Estado en sí mismo, ni se agota en el cumplimiento de reglas de ordenación o el no colapso de los servicios públicos. Dicha protección se relaciona directamente con el mantenimiento de una organización eficiente y adecuadamente constituida, que finalmente busca ofrecer un servicio en beneficio de los ciudadanos para la garantía y vigencia de sus derechos fundamentales. Esta última finalidad es la que le permite al régimen administrativo sancionador-disciplinario compartir el mismo basamento para su intervención que la previsión e imposición de sanciones de índole penal, cual es la protección de bienes jurídicos socialmente relevantes ${ }^{54}$. La diferencia entre la justificación de uno y otro ámbito corresponderá a la intensidad de la afectación de los bienes jurídicos o de su puesta en peligro, o al grado de desvaloración que el ordenamiento jurídico hace de la conducta infractora, reservando para el ámbito jurisdiccional penal las conductas más graves o lesivas de los bienes a proteger.

52 Cf. Pérez Manzano, Mercedes. La prohibición constitucional de bis in idem. Valencia: Tirant lo Blanch, 2002, p. 114. Cf. Huerta Tocildo, Susana. Ob. cit., pp. 45-49. Cf. NAvarRo Cardoso, Fernando. Infracción administrativa y delito: límites a la intervención del derecho penal. Madrid: Constitución y Leyes. S.A., 2001, p. 74.

53 Cf. Asúa BATARRITA, Adela. «La tutela penal del correcto funcionamiento de la administración. Cuestiones político-criminales, criterios de interpretación y delimitación respecto de la potestad disciplinaria». En Delitos contra la administración pública. Bilbao: Instituto Vasco de Administración Pública, 1997, pp. 18-19.

54 OCTAVIO DE TOLEDO Y UBIETO, Emilio. «El delito de prevaricación de los funcionarios públicos». La ley 4139, 1996, p. 3. Citado por HUERTA TOCILDO, Susana. «Principio de legalidad y normas sancionadoras". Actas de las V Jornadas de la Asociación de Letrados del Tribunal Constitucional. El principio de legalidad. Madrid: Centro de Estudios Políticos y Constitucionales, 2000, p. 54. 
La tesis de la unidad del ius puniendi exige, por ende, realizar el análisis y verificación de la identidad de fundamento en los casos de concurrencia de normas prohibitivas y sancionadoras, aun cuando cada una de estas perteneciera a ámbitos distintos, administrativo y penal. No bastará con invocar la distinta naturaleza de los órdenes jurídicos a los que pertenecen tales normas para descartar la identidad de fundamento entre estas.

Por lo tanto, se mantiene la necesidad de contar con un criterio ajustado a los principios del Estado constitucional que permita definir la existencia de la identidad de fundamento entre las intervenciones administrativo-disciplinaria y la jurisdiccional penal, aplicable también a los hechos conocidos por la Contraloría General en sus informes de control respecto de los que concurren las figuras típicas contempladas en la ley 27785, modificada por la ley 29622 y su reglamento, y los tipos que corresponden a los delitos contra la administración pública, contenidos en el Código Penal.

Para tal efecto, el criterio por el que optamos se ha desarrollado en la doctrina constitucional y penal y se ha considerado en algunas sentencias del Tribunal Constitucional peruano ${ }^{55}$. El criterio corresponde a la figura del contenido de injusto o descripción típica de la norma prohibitiva vulnerada por el sujeto incriminado. El contenido de injusto es una forma específica de negación de la prohibición genérica contemplada en el ordenamiento sancionador o una forma específica de afectar el bien jurídico protegido por la norma. En otras palabras, es la descripción específica de la materia prohibida o antijurídica contenida en el tipo objetivo. Es la acción típicamente antijurídica ${ }^{56}$.

Pérez Manzano expresa sobre el particular:

Esta noción de fundamento como interés o razón jurídica concreta es adecuada al fundamento material de la prohibición de doble sanción por cuanto, como se ha sostenido, este reside en la proporcionalidad de las sanciones entendida como proporcionalidad legalizada. Esto es, como el juicio de proporcionalidad que ha quedado plasmado en una concreta norma sancionadora a través de la configuración de sus elementos típicos en cuanto representan el específico contenido desvalorado por el legislador ${ }^{57}$.

Por su parte, Nieto explica que se trata de examinar cuál es el interés jurídicamente protegido contemplado en la norma a través de los

55 Por ejemplo, TRIBUNAL CONSTITUCIONAL. Sentencia recaída en el expediente 10275-2006-HC/TC, Fundamentos Jurídicos 2-5; TRIBUNAL CONSTITUCIONAL. Sentencia recaída en el expediente 049002006-PHC/TC, Fundamento Jurídico 4.

56 Cf. LuZÓn PeÑA, Diego-Manuel. Curso de derecho penal. Parte general. Madrid: Editorial Universitas, S.A. 1996, pp. 329-330.

57 Cf. PÉrez Manzano, Mercedes. Ob. cit., pp. 119-120.

CONTROL GUBERNAMENTAL DEL GASTO PÚBLICO EN EL ESTADO CONSTITUCIONAL: REFLEXIONES A PROPÓSITO DE LA APROBACIÓN DE LAS FACULTADES SANCIONADORAS DE LA CONTRALORÍA GENERAL EN MATERIA DE RESPONSABILIDAD ADMINISTRATIVA FUNCIONAL

GOVERNMENTAL CONTROL OF PUBLIC EXPENDITURE IN THE CONSTITUTIONAL STATE: THOUGHTS REGARDING GENERAL COMPTROLLER SANCTIONING POWERS APPROVAL ON FUNCTIONAL ADMINISTRATIVE RESPONSIBILITY 
elementos constitutivos de la infracción, y en tal sentido, considerar en la evaluación la forma específica de ataque al bien jurídico ${ }^{58}$. Con similar orientación, Benlloch propone analizar si la conducta da lugar a un doble injusto que justifique y legitime, al menos como límite máximo, el doble castigo. Si no se verificara este doble injusto, la doble sanción será una inicua instrumentalización del infractor y de su dignidad como persona ${ }^{59}$.

En definitiva, debe considerarse en el análisis de la identidad de fundamento, frente a pretensiones de persecución y sanción concurrentes, si las normas prohibitivas que describen las infracciones (incluso correspondiendo a órdenes distintos) están desvalorando la misma conducta, así como la forma e intensidad en la que dicha conducta lesiona al bien jurídico afectado. Si así lo fuera, la legitimidad de la persecución y sanción del Estado se agota con una sola de las intervenciones sancionatorias, siendo la otra un exceso de punición estatal y violatoria del principio de proporcionalidad y del derecho al debido proceso en su manifestación a través del ne bis in idem.

\section{b. Contenido de la ley 29622 y su reglamento en relación con el ne bis in idem}

La ley 29622, que amplía las facultades de la Contraloría General de la República para sancionar en materia de responsabilidad administrativa funcional, incorpora en la ley 27785, Ley Orgánica del Sistema Nacional de Control y de la Contraloría General, en el capítulo VII del título III, un subcapítulo II sobre el «proceso para sancionar en materia de responsabilidad administrativa funcional».

La ley define las conductas infractoras en materia de responsabilidad administrativa funcional como «aquellas en las que incurren los servidores y funcionarios públicos que contravengan el ordenamiento jurídico administrativo y las normas internas de la entidad a la que pertenecen».

Las conductas infractoras quedan tipificadas en el artículo 46 de la ley 27785, modificada:

a. Incumplimiento de las disposiciones que integran el marco legal aplicable a las entidades para el desarrollo de sus actividades, así como las disposiciones internas vinculadas con la actuación funcional del servidor o funcionario público.

58 Cf. Nieto García, Alejandro. Derecho administrativo sancionador. Citado por Pérez Manzano, Mercedes. Ibíd.

$59 \mathrm{Cf}$. BENLLOCH, Guillermo. «El principio de non bis in idem en las relaciones entre el derecho penal y el derecho disciplinario». Revista del Poder Judicial, 51 (1998), p. 343. 
b. Incurrir en cualquier acción u omisión que suponga la transgresión grave de los principios, deberes y prohibiciones señalados en las normas de ética y probidad de la función pública.

c. La realización de actos persiguiendo un fin prohibido por ley o reglamento.

d. Incurrir en cualquier acción u omisión que importe negligencia en el desempeño de las funciones o el uso de estas con fines distintos del interés público.

Por otra parte, el mismo artículo establece que «el reglamento describe y especifica estas conductas constitutivas de responsabilidad administrativa funcional (graves o muy graves) que se encuentran en el ámbito de la potestad para sancionar de la Contraloría General. Asimismo, el procesamiento de las infracciones leves será de competencia del titular de la entidad».

En virtud de esta remisión explícita que hace la ley a la norma reglamentaria, el decreto supremo 023-2011-PCM especifica 47 casos de infracciones que corresponden a la competencia sancionadora de la Contraloría General de la República, y que se inscriben en los cuatro supuestos típicos establecidos en la ley.

En relación con la afectación del principio ne bis in idem, cabe destacar que unos mismos hechos conocidos en las acciones de control que implementa la Contraloría General y que son materia del informe de control, podrían evidenciar, simultáneamente, indicios de responsabilidad administrativa y responsabilidad penal. Es decir, tales hechos podrían ser subsumidos tanto por las normas que configuran las infracciones contenidas en la ley 27785, modificada por la ley 29622 y su reglamento, como por las figuras típicas del Código Penal contempladas en el capítulo II del Título XVIII, sobre delitos contra la administración pública cometidos por funcionarios públicos.

CONTROL GUBERNAMENTAL DEL GASTO PÚBLICO EN EL ESTADO CONSTITUCIONAL: REFLEXIONES A

PROPÓSITO DE LA APROBACIÓN DE LAS FACULTADES SANCIONADORAS DE LA CONTRALORÍA GENERAL EN MATERIA DE RESPONSABILIDAD ADMINISTRATIVA FUNCIONAL

GOVERNMENTAL CONTROL OF PUBLIC EXPENDITURE IN THE CONSTITUTIONAL STATE: THOUGHTS REGARDING GENERAL COMPTROLLER SANCTIONING POWERS APPROVAL ON FUNCTIONAL ADMINISTRATIVE RESPONSIBILITY

Se ha señalado que el reglamento de la ley 29622 «contiene descripciones típicas de infracciones administrativas que tienen idéntica estructura o configuración que muchos de los denominados delitos cometidos por funcionarios públicos. En otros casos, dichas infracciones administrativas pueden ser identificadas como modalidades típicas de muchos de los mencionados delitos $»^{60}$.

Así, tenemos como ejemplos el caso de la actuación parcializada en contra de los intereses del Estado en los contratos, licitaciones u otras operaciones (artículo 7 literal h del reglamento) y la negociación 
incompatible o aprovechamiento indebido del cargo (artículo 399 del Código Penal), o el uso indebido o aplicación diferente de los bienes y recursos públicos que han sido confiados al funcionario (artículo 7 literal k del reglamento) y peculado de uso (artículo 388 del Código Penal), u obtener o procurar beneficios o ventajas indebidas haciendo uso del cargo, autoridad, influencia o apariencia de influencia (artículo 7 literal r del reglamento) y el delito de cohecho pasivo impropio (artículo 394 del Código Penal).

Al respecto, se configuraría uno de los supuestos que exigen la aplicación del principio ne bis in idem, es decir, aquella situación que aparentemente es cubierta por dos o más normas prohibitivas pertenecientes a dos órdenes jurídicos distintos — penal y administrativo— y respecto de la cual debe determinarse si corresponde abrir procedimientos simultáneos por cada uno de tales ámbitos para determinar las responsabilidades a que hubiere lugar e imponer sanciones múltiples correspondientes a cada ámbito, o si más bien los hechos identificados en el informe de control solo deben subsumirse en una de las normas prohibitivas para evitar el exceso de sanción.

No obstante, tanto la ley 27785 modificada por la ley 29622 como su reglamento optan por el criterio de la autonomía de responsabilidades entre el ámbito administrativo y el penal, lo que aparentemente conllevaría a interpretar que ambas intervenciones presentan apriorísticamente fundamentos distintos, y por tanto, pueden aplicarse simultáneamente.

Así, el artículo 49 de la ley 27785 establece que:

La responsabilidad administrativo funcional es independiente de las responsabilidades penales o civiles que pudieran establecerse por los mismos hechos, en tanto, los bienes jurídicos o intereses protegidos son diferentes. Los procedimientos para la exigencia de la responsabilidad penal o civil no afectan la potestad para procesar administrativamente y sancionar al funcionario o servidor público que hubiere incurrido en responsabilidad administrativa funcional, salvo disposición judicial expresa en contrario.

Por su parte, el artículo 12 del reglamento en comentario dispone que:

[...] el procesamiento y las sanciones por responsabilidad administrativa funcional son independientes de los procesos y sanciones por responsabilidad civil o penal que pudieran establecerse o determinarse en cada caso.

Solo por disposición judicial expresa se pueden suspender, modificar o eliminar los efectos de las sanciones por responsabilidad administrativa funcional. En caso la disposición judicial expresa recaiga sobre procedimientos en trámite, aquella determinará su suspensión o la 
corrección de los actos a que hubiera lugar. En cualquier caso, la suspensión del procedimiento por decisión judicial expresa acarrea la suspensión de los plazos del procedimiento y los plazos de prescripción.

Una interpretación literal de estas disposiciones llevaría a afectar, restringir e incluso vulnerar el principio ne bis in idem, porque en virtud de la cuestionada teoría de la autonomía de responsabilidades permitiría, a priori y por razones naturalistas, que frente a la concurrencia de normas prohibitivas administrativas y penales se implementaran procedimientos y sanciones múltiples, sin realizar un análisis del fundamento de tales intervenciones y, por tanto, desprotegiendo el derecho a no ser perseguido o sancionado en exceso y vulnerando, consecuentemente, el principio de proporcionalidad y legalidad, basamentos del Estado constitucional y los derechos fundamentales.

Por lo tanto, una aplicación literal de las disposiciones contenidas en el ley 29622 y su reglamento, que absolutizan el criterio de la autonomía de responsabilidades y rechazan analizar la identidad de fundamento en cada caso en concreto de concurrencia de normas administrativas y penales, no resulta compatible con la prohibición constitucional de la persecución y sanción múltiple por los mismos hechos y en virtud del mismo fundamento, ni con los principios de proporcionalidad y garantía de los derechos fundamentales propios del Estado constitucional.

\section{III.2.3.2. El principio de proporcionalidad justifica interpretación de la ley 29622 y su reglamento, conforme a la Constitución, para asegurar su compatibilidad con el principio ne bis in idem}

Si bien la ley 29622 y su reglamento afectan el principio ne bis in idem, también es verdad — como se ha afirmado anteriormente- que dichas normas se han incorporado al ordenamiento jurídico con la finalidad de garantizar bienes constitucionales como la legalidad de la ejecución presupuestal, la eficacia del control gubernamental, la prevención de la corrupción y el buen funcionamiento de la administración estatal.

Así, se configura una relación de conflicto entre bienes, principios o derechos: por un lado, los bienes que la ley 29622 pretendería garantizar, y por el otro, los principios afectados por la misma norma, especialmente el principio ne bis in idem o prohibición de doble persecución o sanción.

El Estado constitucional reconoce la legitimidad de medidas estatales que - como en el caso de las normas en cuestión - puedan constituir una afectación o limitación de derechos o principios constitucionales, siempre y cuando dicha limitación respete el principio de proporcionalidad.

Sobre el principio de proporcionalidad en sentido amplio, se dice que resulta ser el principio más importante del derecho constitucional

CONTROL GUBERNAMENTAL DEL GASTO PÚBLICO EN EL ESTADO CONSTITUCIONAL: REFLEXIONES A PROPÓSITO DE LA APROBACIÓN DE LAS FACULTADES SANCIONADORAS DE LA CONTRALORÍA GENERAL EN MATERIA DE RESPONSABILIDAD ADMINISTRATIVA FUNCIONAL

GOVERNMENTAL CONTROL OF PUBLIC EXPENDITURE IN THE CONSTITUTIONAL STATE: THOUGHTS REGARDING GENERAL COMPTROLLER SANCTIONING POWERS APPROVAL ON FUNCTIONAL ADMINISTRATIVE RESPONSIBILITY 
material $^{61}$ en el marco del Estado constitucional, así como uno de los límites de mayor relevancia a la restricción de los derechos fundamentales en las democracias constitucionales ${ }^{62}$.

En el ordenamiento constitucional peruano, el principio de proporcionalidad se encuentra recogido expresamente en el último párrafo del artículo 200 de la Constitución y con fundamento directo en la cláusula del Estado de derecho. Asimismo, ha sido reconocido por el Tribunal Constitucional como el principio legitimado constitucionalmente para evaluar cualquier acto restrictivo de un derecho fundamental ${ }^{63}$, principio constitucional o bien jurídico protegido constitucionalmente.

Este principio exige que el sacrificio del ejercicio de un derecho fundamental, principio constitucional o bien jurídico protegido constitucionalmente, se encuentre justificado y sea proporcional a la correspondiente necesidad de preservar otro bien o derecho constitucional $^{64}$, asegurando de este modo la interdicción de la arbitrariedad. A pesar de la limitación, el derecho afectado debe realizarse lo más ampliamente posible, de acuerdo con aspectos jurídicos y fácticos que serán valorados, a su vez, de conformidad con los subprincipios de idoneidad, necesidad y proporcionalidad en sentido estricto ${ }^{65}$.

En este orden de consideraciones, reconociendo que la ley 29622 y su reglamento, protegen bienes constitucionales de primer orden, corresponde anotar que su adecuación y necesidad en relación con la protección de dichos bienes queda evidenciada por la debilidad de la eficacia del control de la actuación de los funcionarios y servidores públicos, cuando las facultades sancionadoras por responsabilidad administrativa funcional se han preservado exclusivamente en poder de los titulares de las instituciones públicas.

Al respecto conviene citar el dictamen que recayó sobre el proyecto de ley que ampliaba las facultades sancionadoras de la Contraloría General de la República durante su proceso de aprobación en el Congreso de la República.

El proyecto se fundamenta principalmente en la inobservancia en la implementación de las recomendaciones emanadas de los informes

61 Cf. ALEXY, Robert. «La fórmula del peso». En Miguel Carbonell y Pedro Grandez. El principio de proporcionalidad en el derecho contemporáneo. Lima: Palestra Editores. 2010, p. 14.

62 Cf. CLÉRICO, Laura. «El examen de proporcionalidad: entre el exceso por acción y la insuficiencia por omisión o defecto». En Miguel Carbonell y Pedro Grandez. El principio de proporcionalidad en el derecho contemporáneo. Lima: Palestra Editores. 2010, p. 115.

63 TriBunal Constitucional. Sentencia recaída en el expediente 0010-2002-AI/TC. Fundamentos Jurídicos 195-197.

64 Cf. Prieto Sanchís, Luis. Derechos fundamentales, neoconstitucionalismo y ponderación judicial. Lima: Palestra Editores, 2002, pp. 62-64.

65 Cf. AleXY, Robert. Ob. cit. pp. 14-15. 
de control —que señalan la responsabilidad administrativo funcional— en que incurren las entidades que reciben los informes de control y que no permiten deslinde de responsabilidades y consecuentemente la aplicación de las sanciones que correspondan. Situación que la Contraloría General de la República refiere que ha significado que, por ejemplo, de un total de 466 recomendaciones efectuadas por dicha entidad, entre los años 2001 a 2010, el 34\% de estas hayan culminado los procesos administrativos sancionadores, quedando un $27,04 \%$ en proceso de implementación y el resto pendientes [...] señala que se debe a diversos factores, entre los cuales se encuentran: a) la ausencia de un procedimiento uniforme para el deslinde de responsabilidades, debido a que en la administración pública coexisten diversos regímenes laborales, b) El hecho de que sea la propia entidad la que se encarga de sancionar a su personal ${ }^{66}$.

Por lo tanto, resulta necesaria una medida como la que propone la ley 29622 y desarrolla su reglamento, al otorgar facultades sancionadoras a la Contraloría General en materia de responsabilidad administrativa funcional, pero haciendo una interpretación conforme a la Constitución y al principio ne bis in idem, de forma que la restricción que plantea respecto de tal principio resulte proporcionada y legítima constitucionalmente, en orden a la satisfacción de las finalidades de legalidad de la ejecución del presupuesto y adecuado uso de los recursos públicos, buen funcionamiento de la administración estatal, eficacia del control gubernamental, así como prevención y lucha contra la corrupción.

En consecuencia, el presente artículo plantea realizar una interpretación conforme a la Constitución de las referidas disposiciones contenidas en la ley 29622, de modo que puedan preservarse en el ordenamiento jurídico a través de la prevalencia del sentido interpretativo de aquellas que cumpla con ajustarse a los principios constitucionales del ne bis in idem y proporcionalidad en el ámbito administrativo disciplinario o funcional.

Para ello, se propone tener en cuenta los siguientes criterios:

- Con relación a la aplicación del principio ne bis in idem, a los supuestos bajo comentario, la triple identidad, persona, hechos y fundamento deben orientar al operador jurídico para determinar la norma prohibitiva y sancionadora aplicable.

- La identidad de fundamento debería definir la procedencia y articulación de las intervenciones penal y administrativa, respecto

CONTROL GUBERNAMENTAL DEL GASTO PÚBLICO EN EL ESTADO CONSTITUCIONAL: REFLEXIONES A PROPÓSITO DE LA APROBACIÓN DE LAS FACULTADES SANCIONADORAS DE LA CONTRALORÍA GENERAL EN MATERIA DE RESPONSABILIDAD ADMINISTRATIVA FUNCIONAL

GOVERNMENTAL CONTROL OF PUBLIC EXPENDITURE IN THE CONSTITUTIONAL STATE: THOUGHTS REGARDING GENERAL COMPTROLLER SANCTIONING POWERS APPROVAL ON FUNCTIONAL ADMINISTRATIVE RESPONSIBILITY 
de los hechos y responsabilidades identificadas en los informes de control.

- La existencia o no de identidad de fundamento entre las normas sancionadoras que concurren respecto de las conductas irregulares identificadas en los informes de control a cargo de la Contraloría General debería ser analizada, tomando como criterio el contenido de injusto o el reproche específico que el ordenamiento jurídico realiza respecto de las conductas prohibidas. Para ello se debería comparar la descripción típica que realizan las normas prohibitivas para determinar si se trata de formas idénticas de afectar los bienes jurídicos involucrados o no. Este análisis debería realizarse en cada caso concreto y variará según las circunstancias de cada caso.

- En el caso de que el contenido de injusto coincida aparentemente, tanto en la norma penal como en la norma administrativa, que podría aplicarse a los hechos y conductas objeto de conocimiento del operador jurídico, verificándose la identidad de hechos y fundamento, correspondería subsumir tales hechos y conductas solo en una de las normas prohibitivas que absorba íntegramente dicha conducta, en aplicación del principio ne bis in idem.

- La determinación de la norma a aplicarse, penal o administrativa, debería analizar el alcance de lo prohibido en cada norma, y definirse por aquella que desvalore adecuada y proporcionalmente las conductas investigadas, asignándole una consecuencia que cumpla con las finalidades de prevención de lesión o puesta en peligro de bienes jurídicos.

- El alcance de lo prohibido debería tener en cuenta, entre otros, la gravedad de los hechos, considerando que el derecho penal es última ratio y que, por el principio de fragmentariedad, se reserva las conductas más lesivas a los bienes jurídicos afectados. Asimismo, debería considerase en el análisis el dolo y los elementos de tendencia interna trascendente. $\mathrm{Al}$ respecto, conviene destacar que el artículo 12 del Código Penal establece que «las penas establecidas por la ley se aplican siempre al agente de infracción dolosa. El agente de infracción culposa es punible en los casos expresamente establecidos en la ley», por lo que, salvo el delito de peculado previsto en el último párrafo del artículo 387 del Código Penal, todos los delitos contra la administración pública cometidos por funcionarios públicos son modalidades dolosas. Por tanto, no correspondería atribuir responsabilidad penal a los actos y conductas culposas de modo general. Estas deberían ser investigadas y, eventualmente, sancionadas en el ámbito administrativo. La misma consecuencia debe operar si no se verificara en la actuación del funcionario o servidor público, 
los elementos de tendencia interna trascendente, es decir, los propósitos o fines que determinan la conducta descrita en el tipo penal. Otros elementos a involucrar en el análisis de cada caso serán la existencia o no de una causa de justificación para actuar, en el sentido cuestionado penalmente, la presencia de error sobre la conducta prohibida o la adecuación social de la conducta $^{67}$.

- En el caso de que de la comparación del contenido de injusto de cada una de las normas prohibitivas se hubiera desprendido que son notoriamente distintas y que, por tanto, se trata de un fundamento de punición diferente en cada caso, sí correspondería implementar los procedimientos para la investigación penal y administrativa simultáneamente, y aplicar las sanciones que correspondieran a cada ámbito. En este supuesto, los tipos concurrentes resultarán complementarios y desvalorarán conjuntamente, de forma integral, la conducta o los hechos en cuestión.

- El artículo 49 de la ley 27785, modificada por la ley 29622, y el artículo 12 de su reglamento, referidos a la autonomía de responsabilidades, debería interpretarse asumiendo que tal autonomía o independencia de responsabilidades se verificará solo cuando el fundamento de cada una de las intervenciones punitivas, penal y administrativa, sea distinto, lo que deberá analizarse en cada caso en concreto $^{68}$.

- Por lo tanto, el artículo 49 de la ley que señala que:

La responsabilidad administrativo funcional es independiente de las responsabilidades penales o civiles que pudieran establecerse por los mismos hechos, en tanto los bienes jurídicos o intereses protegidos son diferentes. Los procedimientos para la exigencia de la responsabilidad penal o civil no afectan la potestad para procesar administrativamente y sancionar al funcionario o servidor público que hubiere incurrido en responsabilidad administrativa funcional, salvo disposición judicial expresa en contrario (cursiva nuestra).

67 Pereira Chumbe, Roberto. Ob. cit.

68 En similar sentido se ha pronunciado Benlloch cuando se refiere a la ley española del régimen jurídico de las administraciones públicas y del procedimiento administrativo común, interpretando que la fórmula de la triple identidad es aplicable al ámbito administrativo disciplinario, a pesar de que la citada ley excluye el principio de ne bis in idem a la materia disciplinaria funcionarial. Apoya su afirmación en el hecho de que el principio ne bis in idem ha sido consagrado por la jurisprudencia del Tribunal Constitucional como un principio implícito en el de legalidad contemplado en el artículo 25 de la Constitución española. Sobre el particular, anota que el Tribunal Constitucional sí parece consciente de que la garantía del ne bis in idem se impone incluso al legislador, pues ha indicado que «no basta simplemente con la dualidad de normas para entender justificada la imposición de una doble sanción al mismo sujeto por los hechos, pues si así fuera, el principio ne bis in idem no tendría más alcance que el que el legislador (o en su caso el gobierno, como titular de la potestad reglamentaria) quisiera darles» ver: STC 234-91 de 10 de diciembre de 1991». BENLLOCH, Guillermo. Ob. cit., pp. 371-372. 
Debería interpretarse del siguiente modo:

La responsabilidad administrativo funcional es independiente de las responsabilidades penales o civiles que pudieran establecerse por los mismos hechos, en tanto, su afectación a los bienes jurídicos o intereses protegidos sea diferente (cursiva nuestra).

Ello se condice con la disposición que forma parte del mismo artículo 49, que señala que el juez puede disponer la suspensión del procedimiento administrativo sancionador, entendiéndose que se admite la posibilidad de que la intervención penal y administrativa pueden compartir el mismo fundamento, lo que se determinará en el conocimiento y análisis de cada caso en concreto.

El mismo razonamiento puede aplicarse al artículo 12 del reglamento, en función de la prevalencia y determinación que reconoce al ámbito jurisdiccional penal, para definir si corresponde continuar con el procedimiento administrativo sancionador o suspenderlo, modificar o eliminar las sanciones administrativas, lo que solo puede afirmarse si se reconoce como presupuesto que podría haber identidad de fundamento en las intervenciones penal y administrativa, y por lo tanto, descartar una autonomía absoluta de responsabilidades en cada ámbito.

\section{REFLEXIÓN FINAL}

Siguiendo a Asúa Batarrita, resulta claro que si la corrupción y la mala utilización de recursos públicos afectan la calidad de los servicios que el Estado presta a la ciudadanía o alteran los procedimientos que garantizan el acceso a los bienes sociales en condiciones de igualdad, tales problemas merecen ser considerados como un atentado contra los derechos humanos ${ }^{69}$. Esta afirmación cobra especial importancia en un contexto como el actual, caracterizado por el crecimiento económico —que se ha traducido en mayores recursos en poder de la administración pública - así como por la intensificación de las demandas ciudadanas de equidad, inclusión y desarrollo social.

En atención a ello, hemos querido contribuir al proceso de constitucionalización del ordenamiento jurídico, desde una aproximación al ámbito del control externo del gasto público y de la actuación de la Contraloría General de la República. Ello ha supuesto interpretar la relevancia de dicho organismo y de su función de control sobre la utilización de los recursos públicos, en la perspectiva del Estado constitucional, destacando su aporte a la realización de finalidades de primer orden en el Estado, como legalidad de la ejecución presupuestal 
y adecuada gestión de recursos públicos, el buen funcionamiento de la administración estatal, «la eficiencia de las necesidades sociales»y la prevención de la corrupción. De ello se ha deducido la legitimidad del reconocimiento de facultades a este organismo que fortalezcan la eficacia del cumplimiento de sus funciones.

No obstante, el mismo proceso de constitucionalización del control externo del gasto público exigirá que el ejercicio de las potestades de la Contraloría General, entre ellas la ampliación de sus competencias para determinar y sancionar la responsabilidad administrativa funcional, se encuentren arregladas a la Constitución y a los principios que garantizan la proscripción de la arbitrariedad y el respeto de los derechos fundamentales de quienes se hallan bajo su ámbito de control.

Así, consideramos que resulta fundamental el papel que debe jugar el derecho constitucional en el análisis de los problemas planteados y en la definición de criterios jurídicos que contribuyan a articular y optimizar las finalidades, bienes y derechos constitucionales en juego. El presente artículo pretende contribuir a los esfuerzos que al respecto se desarrollen, con miras a apoyar el proceso de afirmación de una Contraloría General promotora de la transparencia, la ética pública, la prevención de la corrupción y, en definitiva, de un Estado al servicio de los ciudadanos y ciudadanas.

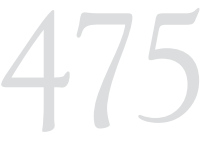

CONTROL GUBERNAMENTAL DEL

GASTO PÚBLICO

EN EL ESTADO

CONSTITUCIONAL:

REFLEXIONES A

PROPÓSITO DE LA

APROBACIÓN DE

LAS FACULTADES

SANCIONADORAS

DE LA CONTRALO-

RÍA GENERAL EN

MATERIA DE RES-

PONSABILIDAD

ADMINISTRATIVA

FUNCIONAL

GOVERNMENTAL

CONTROL OF

PUBLIC EXPEN-

DITURE IN THE

CONSTITUTIONAL

STATE: THOUGHTS

REGARDING

GENERAL COMP-

TROLLER SANC-

TIONING POWERS

APPROVAL ON

FUNCTIONAL

ADMINISTRATIVE

RESPONSIBILITY 